\title{
Exploring Emerging Modal Plant Tomato's Crop Biology, Nutrition, Production and Evolving Employments
}

\section{Javed MW*, Ahmad JN and Ahmad SJN}

Integrated Genomics, Cellular, Developmental and Biotechnology Laboratory, Department of Entomology, University of Agriculture, Faisalabad, Pakistan

*Corresponding author: Muhammad Wajid Javed, Editor, Open Access Journal of

\section{Editorial}

Volume 3 Issue 8

Received Date: September 18, 2018

Published Date: September 20, 2018

Agricultural Research. Integrated Genomics, Cellular, Developmental and Biotechnology Laboratory, Department of Entomology \& Plant Stress Physiology and Molecular Biology Laboratory, Department of Botany, University of Agriculture, Faisalabad, Pakistan, Email: muhammadwajidjaved@gmail.com

\section{Editorial}

Tomato technically referred Lycopersicon esculentum Mill is a well-known vine plant with dicot habit of family Solanaceae, botanically included in fruit class with multiple synonymous nomenclature of Solanum lycopersicum and Lycopersicon lycopersicum with widely determined and well crowned kitchen and medical employments [1,2]. Solanaceae or Nightshade family involves association signs with multitude of commercially indispensable plants such as potato, eggplant, chilli peppers, tobacco plant and petunia members [3]. Tomato is an important cash and commercial crop of the world food sector [4].

Tomato contains a better amount of carbohydrate, dietary fibre, vitamin A, vitamin C, total sugars, calcium and also medically essential iron, phosphorous and carotene-lycopene; a strong antioxidant with good contribution to reduce cancer forms and cardiovascular diseases [5,6]. Due to good amount of vitamin $A$ and vitamin $C$, there are least chances of muscular deformities and enhanced eye sight; with other associated benefits possess tomato role as blood purifier with much dominance [2]. This crop has exceptional enhancement with tonnage and area seeded visible from day by day high demand [7]. Tomato is qualitatively better vegetable plant with origin area of western south America, nowadays planted in country Peru, and later cultivation noticed in central American localities [3,8].
L. esculentum crop is necessary in regular use of human food with accomplishment for various dietary needs [1]. Tomato is harvested on larger areas of eastern and western regions of global recognitions and wide cultivation significantly in Mediterranean world territories [9]. Tomato scientifically regarded $L$. esculentum is one with the great consumption based entity on the world rank with various desirability of employments such as food taste increments, cooking dresser, ketchup, juice and also in a number of other cooking orientations [1]. This crop is also has a great potential for increase in employment and job opportunities worthier for rural and peri-urban low income people with no suitable earning means [2].

In 2014 database records, China ranked first globally in tomato production with about 50 million tonnes. Being provided with wide possessions of daily uses, this crop is grown at country and out border fields with cultivation of 58196 hectares in Pakistan with associated cropping yield of tomato plants and production parameters worthier $98641 \mathrm{Hg} / \mathrm{Ha}$ and 574052 tonnes crop producing terms [10]. Tomato plant is comprehended as modal botanical based individual for various degrees contain parameters of short life cycle with new cultivated variety of tomato plant "Microtom" with 70 to 90 days' time cropping time allocation and chromosome diploid numbering 24 [2n] with genome size of $950 \mathrm{Mbps}$ [i.e., 77\% heterochromatin and $23 \%$ euchromatin chromosomal part contribution] $[11,12]$. 


\section{Open Access Journal of Agricultural Research}

Tomato is also grown as widely for research plant material as it is categorized in "Emerging Modal Individual" by Cold Spring Harbor Protocols due to distinct qualities of fleshy fruits, compound broader leaves and sympodial or pseudaxis, not present in other modal plants comprising Arabidopsis thaliana and rice [3]. By considering the increasing levels of $5 \%$ in the represented tomato crop and 8\% enhancement in area grown of tomato crop, there is fundamental provision to improve the Pakistan tomato export quality and commodity limits [1].

A huge contributor factors comprising low or least standard quality seeds, insect pests options and disease prevalence by pathogenic organisms are vital parameters producing decrement in tomato yield in the territorial limits of Pakistan consisting insect pests being the one and much important yield reducing partners with any form of losses either of quality or quantity terms for insect occurrence [13-15]. These need to be addressed as earlier as possible to employ the tomato crop potential on the highest dynamics.

\section{References}

1. Tahir A, Shah H, Sharif M, Akhtar W, Akmal N (2012) An overview of tomato economy of Pakistan: Comparative analysis. Pak J Agri Res 25(4): 288-294.

2. Arah IK, Kumah E, Anku E, Amaglo H (2015) An overview of post-harvest losses in tomato production in Africa: Causes and possible prevention strategies. J Biol Agric Healthcare 5(16): 78-88.

3. Kimura S, Sinha N (2008) Tomato (Solanum lycopersicum): A model fruit-bearing crop. CSH Protoc 11: 1-9.

4. Ayandiji A, OR A, Omidiji D (2011) Determinant post harvest losses among tomato farmers in Imeko-afon local government area of Ogun state, Nigeria. Global J Sci Frontier Res 11(5): 1-7.

5. Arthur E, Oduro I, Kumah P (2015) Postharvest quality response of tomato (Lycopersicon esculentum, Mill) fruits to different concentrations of calcium chloride at different dip-times. Am J Food Nutr 5(1): 1-8.
6. Freeman BB, Reimers K (2010) Tomato consumption and health: Emerging benefits. Am J Life Med 5: 182191.

7. Ha TM (2015) Agronomic requirements of tomatoes and production methods in the red river delta of Vietnam. J Tropic Crop Sci 2(1): 1-12.

8. Tan H, ThomasAhner JM, Grainger EM, Wan L, Francis DM, et al. (2010) Tomato-based food products for prostate cancer prevention: What have we learned? Canc Metast Rev 29(3): 553-568.

9. Nombela G, Pascual S, Aviles M, Guillard E, Muñiz M (2005) Benzothiadiazole induces local resistance to Bemisia tabaci (Hemiptera: Aleyrodidae) in tomato plants. J Econ Entomol 98(6): 2266-2271.

10. FAOSTAT (2015) Food and Agriculture Organization of the United Nations Statistics Division 2015.

11. Dan Y, Yan H, Munyikwa T, Dong J, Zhang Y, et al. (2006) MicroTom-a high-throughput model transformation system for functional genomics. Plant Cell Rep 25(5): 432-441.

12. Passam HC, Karapanos IC, Bebeli PJ, Savvas D (2007) A review of recent research on tomato nutrition, breeding and post-harvest technology with reference to fruit quality. Eur J Plant Sci Biotechnol 1(1): 1-21.

13. Usman A, Khan IA, Inayatullah M, Saljoqi AUR, Shah M (2013) Appraisal of different tomato genotypes against tomato fruit worm (Helicoverpa armigera Hub.) infestation. Pak J Zool 45(1): 113-119.

14. Hoffmann H, Hardie D, Burt J (2007) Tomato pests in the home garden and their control. Dept Agri Aust Garden Note 34: 82-88.

15. Javed MW (2016) Study on induced resistance based defense genes expression to control consequential insect pests of tomato (Lycopersicon esculentum). MSc (Hons) Thesis, Department of Entomology, University of Agriculture Faisalabad. 